\title{
O surgimento das companhias 2: uma pretensa "nova" forma de organização profissional de bailarinos que atingem idade em torno de 40 anos nas companhias públicas de dança brasileiras
}

\author{
Ana Cristina Echevenguá Teixeira ${ }^{1}$
}

\section{Resumo}

A intenção deste artigo é lançar luz sobre uma realidade bastante particular no contexto das companhias públicas de dança brasileiras, que começa a se delinear a partir do final dos anos 1990. Trata-se de assunto delicado e que ficou à margem das discussões que norteiam o universo da dança dessas companhias: o surgimento das companhias 2, uma pretensa "nova" forma de organização profissional de bailarinos que atingem idade em torno de 40 anos. Implementadas, em geral, nessa época, pelos seus diretores, essas companhias se constituem de bailarinos denominados "intérpretes-criadores", que fazem da sua maturidade artística uma ignição para a conquista de novos caminhos para a sua carreira.

Palavras-chaves: companhia de dança pública brasileira, companhias 2, intérprete-criador, dançaEstado.

The emergence of the second companies: A so-called "new" form of organization for professional dancers reaching age around $\mathbf{4 0}$ years at the public dance companies in Brazil.

\begin{abstract}
This article focuses a very particular reality within the context of Brazilian public dance companies, which started to take shape during the last years of the 1990's. It concerns a touchy subject, which has been left aside from discussions that give direction to the dance universe of these companies: the creation of the company 2, a pretense "new" form of organization of professional dancers around 40 years old. Implemented in general by their directors, these companies are formed with the dancer called "dancer-creator" ("intérprete-criador"). Dancers make of their artistic maturity an ignition towards new possibilities for their carriers.
\end{abstract}

Keywords: Brazilian public dance companies, companies 2, dancer-creator, dance-State.

\section{O ambiente das companhias $2^{2}$ - As companhias públicas de dança brasileiras}

Entendem-se, aqui, como companhias públicas de dança, de modo geral, as companhias criadas em lei e sustentadas pelo dinheiro público. A verba pode vir dire-

\footnotetext{
${ }^{1}$ Artista, consultora e pesquisadora na área da dança. Doutoranda em Comunicação e Semiótica (PUC-SP CNPq) e mestre pela mesma instituição. É formada em Educação Física pela Universidade de Caxias do Sul (1992) e em Arts du Spectacle Mention Danse pela Université Paris VIII (França-2002). Foi diretora artística assistente do Balé da Cidade de São Paulo (2003 a 2009). Atualmente, é consultora para o programa Dança Contemporânea da SESC TV-SP e pesquisadora para a Enciclopédia Itaú Cultural de Dança.

2 Salienta-se que, quando a referência for relacionada à companhia 2, como designação geral, será mantida por extenso.
} 
tamente do orçamento oficial ou por meio de benefícios fiscais via leis de incentivo. Por fazerem parte dos equipamentos gerenciados pelo poder público, essas companhias obedecem ao que o Estado regulamenta para a sua estrutura de funcionamento. Além de "corpo de baile,' "companhia pública" e "companhia oficial", elas são também chamadas de companhias estáveis, corpos estáveis, corpos artísticos e equipamentos artísticos ou culturais, e essa pluralidade opera inespecificamente produzindo um tipo de comportamento social que interfere nos seus processos de comunicação.

A vinculação das companhias com a administração pública e, consequentemente, com os órgãos públicos que as abrigam tem distintas formas jurídicas. Elas podem se estabelecer das seguintes maneiras: a) forma direta: quando compostas pelas suas entidades estatais, nesse caso estados e municípios, sem personalidade jurídica própria; b) forma indireta: quando compostas por entidades autárquicas, fundacionais e organizações sociais.

A existência da lei, do decreto ou da portaria é a postulação que determina se uma companhia é pública ou privada. Dessa forma, faz-se necessário entrar em contato com o significado de cada uma dessas expressões, mesmo que num sentido mais amplo. A lei, conforme o Dicionário Houaiss da Língua Portuguesa (2009, p. 1.165): "é uma prescrição escrita que emana da autoridade soberana de uma dada sociedade e impõe a todos os indivíduos a obrigação de submeter-se a ela sob pena de sanções". Decreto, para Di Pietro³ (2010, p. 233), "é a forma de que se revestem os atos individuais ou gerais, emanados do Chefe do Poder Executivo (Presidente da República, Governador e Prefeito)", e portaria "é a forma de que se revestem os atos, gerais ou individuais, emanados de autoridades que não o Chefe do Executivo" (p. 233). A forma descrita de cada companhia deve ser levada em conta no prisma que se refere ao entendimento de seu papel na dança. Existem tipos diferentes de leis, tendo em vista que cada companhia está sediada numa determinada localidade, traduzindo de maneira similar seus anseios no que se refere à função da companhia.

Uma viagem ao passado pode orientar sobre a oficialização da dança, quer dizer, quando ela passa a ser abrigada pela administração pública. Esse formato tem como marco o ano de 1661, quando o rei da França, Luís XIV (1638-1715) funda a Academia Real de Dança, dando início, na cidade de Paris, à profissionalização da

${ }^{3}$ Maria Sylvia Zanella Di Pietro, professora titular de Direito Administrativo na Faculdade de Direito da Universidade de São Paulo (USP). 
dança e garantindo, mais adiante, renda fixa aos dançarinos das óperas. O historiador de dança britânico Ivor Guest afirma que:

Sob o augusto patrocínio de Luís XIV, o Rei Sol, a dança começou a adquirir
a dignidade e o respeito merecido que, desde então, nunca deixaram de
cercar essa arte. A criação da Academia Real de Dança, em 1661, foi a
primeira demonstração explí́ita da importância atribuída pelo soberano
a um ensinamento coreográfico de alto nível. Apesar de essa instituição
não ter tido uma influência notável sobre a evolução da dança teatral, o
simples fato de sua fundação testemunha a importância que tinha a dança
entre os divertimentos da corte e da capital. Mas outro fato seria ainda mais
significativo: a criação em 1669, por carta patente, da Academia da Ópera,
a qual já abrigava a semente da futura Ópera de Paris. ${ }^{4}$ (GUEST, 1976, p.
1- grifo nosso)

Esse parâmetro parisiense invade as cortes europeias e se desenvolve em muitos países. Valendo-se do pensamento de Canclini (1980, p. 44), quanto a esse caso específico, pode-se destacar a seguinte passagem: "A dependência cultural obriga-nos a viver uma relação de apropriação retardada: 'nossa' arte é o resultado do que outras já fizeram; em vez de uma produção, é uma mera reprodução".

Essa citação aborda uma reflexão, até então inexistente quando se trata da criação das companhias brasileiras, apoiadas nesse paradigma de relação da dança na esfera pública. Para tanto, necessita-se avaliar de maneira ponderada essas inoculações que importamos no âmbito da dança pública e que produziram graves problemas na sua construção, pois sua origem se constituiu de fora para dentro. Nesse ponto, nos estudos sobre tradução cultural desenvolvidos por Santos (2006, p. 46), é abordada a problemática gerada pelo uso inadequado das teorias herdadas, ou seja, aquelas que se adaptam a uma realidade social diferente daquela em que a teoria nasceu, pois, como o autor salienta:

[...] quem somos nós nesse espaço de língua oficial portuguesa, nas nossas diferenças e cumplicidades integrados num mundo crescentemente globalizado, segundo uma lógica em cujo desenho temos, quando muito, uma participação subordinada, uma lógica que ou trivializa ou, pelo contrário, dramatiza as nossas diferenças, mas, em qualquer caso, bloqueia a construção das cumplicidades.

Dessa forma, é o mesmo Santos (2006, p. 127) que alerta sobre a importância dos processos tradutórios entre culturas, dizendo: "O trabalho de tradução visa esclarecer o que une e o que separa os diferentes movimentos e as diferentes práticas, de modo a determinar as possibilidades e os limites da articulação ou agregação entre eles." Na visão desse teórico, o processo tradutório entre distintas culturas seria a

\footnotetext{
${ }^{4}$ Tradução nossa.
} 
chave para a consolidação de uma alternativa não hegemônica, entendendo a boa tradução como aquela que conduz a uma pluralidade de experiência e combinação de procedimentos em diversas vias, e é nessa abordagem que o termo "tradução" pode ser pensado na perspectiva cultural das companhias públicas.

A primeira companhia brasileira pública criada a partir desse modelo é o Corpo de Baile do Theatro Municipal do Rio de Janeiro, em 1936, atual Ballet do Theatro Municipal do Rio de Janeiro. Dirigido pela bailarina, coreógrafa e professora russa Maria Olenewa (1896-1965), que fixa residência no Brasil, em 1926, após uma de suas passagens pelos palcos brasileiros acompanhando as companhias russas de Anna Pavlova (1881-1931) e Léonide Massine (1895-1979). Esse corpo de baile é fruto da primeira escola de dança pública criada em 1927, também na cidade do Rio de Janeiro. Denominada Escola de Bailados do Theatro Municipal, teve como mentores a própria Olenewa e o crítico de teatro Mário Nunes (1886-1968). Em 1982, quase 50 anos depois, o nome muda para Escola Estadual de Dança Maria Olenewa, em sua homenagem.

O corpo de baile carioca nasce com a tarefa de cumprir profissionalmente as temporadas dos teatros de ópera. Durante esse período, que vai do início dos anos 1930 até o final dos anos 1960, a formação de bailarinos na técnica do balé clássico é fundamental. Desse modo, a grande maioria selecionada para compor o elenco é proveniente da própria escola. Se, de início, os corpos de baile acompanhavam as óperas, com o passar dos anos outra dinâmica artística entra em vigor. Desvencilhados dessa obrigação, eles vão se transformando em companhias profissionais e definindo o próprio estilo artístico e a programação anual. No final do século $X X$, a relação entre escola e companhia torna-se menos implícita, não havendo mais a necessidade dessa ligação para contratar um bailarino.

Ao referir-se a esse formato de estrutura, Katz (2003, p. 109) diz:

Um Corpo de Baile nasce das diversidades (vários corpos) compactadas no singular (Corpo de Baile), indicando que devem ambicionar serem vistos como um só. Para isso, precisam se apresentar com uma mesma feição. Sem nome próprio, tal como seus bailarinos, portanto somente uma classificação genérica de espécie, tende a ser identificado pelo local que o abriga, geralmente algum teatro oficial. Um Corpo de Baile é sempre um Corpo de Baile de algum lugar, seja de um teatro, ou um município ou uma regiãoforma de existir/ser nomeado que escancara uma natureza de prestador de serviço. Nascer assim é quase como nascer com a vida traçada. 
Desde que a primeira companhia brasileira oficial foi fundada, em 1936, foi possível mapear a existência de $17^{5}$ delas, distribuídas pelas regiões Sul, Sudeste, Centro-Oeste, Nordeste e Norte do nosso território. São elas: 1. Ballet do Theatro Municipal do Rio de Janeiro (RJ, 1936); 2. Balé da Cidade de São Paulo (SP, 1968); 3. Balé Teatro Guaíra (PR, 1969); 4. Cia. de Dança Palácio das Artes (MG, 1971); 5. Balé do Teatro Castro Alves (BA, 1981); 6. Balé da Cidade de São José do Rio Preto (SP, 1987); 7. Companhia de Ballet da Cidade de Niterói (RJ, 1992); 8. Balé da Cidade de Teresina (PI, 1993); 9. Companhia Municipal de Dança de Caxias do Sul (RS, 1997); 10. Companhia de Dança do Amazonas (AM, 1998); 11. Balé do Estado de Goiás (GO, 1999); 12. Balé da Cidade de Natal (RN, 2002); 13. Balé da Cidade de Taubaté (SP, 2006); 14. Companhia Municipal de Dança de Belém (PA, 2006); 15. Bailare - Cia. Municipal de Dança (Vacaria/RS, 2008); 16. São Paulo Cia. de Dança (SP, 2008); 17. Corpo Estável do Polytheama (Jundiaí/SP, 2011). Dentre elas, a que mantém vínculo com o repertório clássico é o Ballet do Theatro Municipal do Rio de Janeiro. Mas em todas, inclusive nessa, transitam coreógrafos nacionais e estrangeiros das várias linguagens da dança clássica, moderna e contemporânea.

As companhias oficiais são projetadas por funcionários administrativos sem familiaridade com as questões relativas à natureza artística da dança profissional, o que termina por replicar, na estrutura funcional delas, principalmente das mais antigas, o modelo burocrático da administração pública. $O$ fato de não serem projetadas por especialistas em dança reverte-se na implantação de uma estrutura sem aptidão para abrigar as especificidades indispensáveis ao seu bom funcionamento. Esse fato não promove somente entraves de natureza administrativa, mas atinge, também, o seu direcionamento artístico. Como aponta Canclini (1980, p. 29):

\section{As classes dominantes estão unicamente interessadas em reproduzir as condições de produção e as relações sociais que as beneficiem; os artistas que servem a esses interesses ou, pelo menos, aceitam seu enquadramento ideológico, concebem a sua prática como a representação da ordem existente: a uma política da reprodução corresponde uma estética de representação.}

A gravidade dos efeitos desse tipo de vínculo, contaminado pelas circunstâncias coloniais de subordinação, pode ser percebida nas dificuldades operacionais comuns a todas as companhias oficiais: contratação de pessoal, morosidade nos processos, problemas orçamentários, invisibilidade, comunicação precária com os

${ }^{5}$ Essas são as companhias mapeadas até o momento (setembro de 2011); podem existir outras ainda não apontadas neste artigo. 
superiores, engessamentos, resultando em falta de autonomia e várias outras implicações. De acordo com os poucos documentos encontrados sobre as companhias que aqui importaram esse modelo que produz certo modo de pensar a dança, é possível perceber nelas a vinculação à sociedade aristocrática que as produziu. Assim sendo, as companhias desenvolvem suas funções artísticas oficiais, produzindo um discurso complexo de caráter jurídico. Devido à sua natureza funcional e administrativa de organização e funcionamento, essas companhias tornam-se produtos de dupla articulação vinculados ao Estado: o sistema de poder que Ihes permite hoje existir e aquele no qual foram criadas. Para lidar com a complexidade dessa situação, cita-se Thompson (1995), que se dedica aos estudos das relações entre mídia e poder:

\begin{abstract}
Todas as organizações implicam algum grau de coordenação e de regulamentação, e por isso também um certo grau de poder político neste sentido. Mas nós podemos identificar uma gama de instituições que se dedicam essencialmente à coordenação e à regulamentação, e que desempenham estas atividades de uma maneira relativamente centralizada dentro de um território mais ou menos circunscrito. Estas instituições abrangem o que geralmente é conhecido como estado - a instituição paradigmática do poder político. Historicamente houve muitas formas de estado, desde os tradicionais estados imperiais, passando pelas cidade-estado da idade clássica, até as modernas formas de estado-nação. Todos os estados, ou instituições paraestatais, são essencialmente sistemas de autoridade. Implicam um complexo sistema de regras e procedimentos que autorizam certos indivíduos a agirem de determinadas maneiras. Em alguns casos estas regras e procedimentos são explicitamente codificados em forma de leis promulgadas por corporações soberanas e administradas por um sistema judicial. (p. 23)
\end{abstract}

Em outras palavras, significa que, para falar em companhias oficiais de dança, é necessário tocar nas complexas relações entre arte e poder.

\title{
Da contratação dos bailarinos dessas instituições
}

Os "corpos artísticos", como são designados os bailarinos nos documentos jurídicos e administrativos, são regidos, na sua maioria, pela lei do servidor público de um estado. "Servidores públicos", segundo Di Pietro (2010, p. 512), "é a expressão para designar as pessoas que prestam serviços, com vínculo empregatício, à administração pública direta, autarquias e fundações públicas." Para integrar o elenco de uma companhia, o bailarino deve ter registro profissional na DRT (Delegacia Regional do Trabalho) e prestar concurso público, audição pública ou ser convidado, em alguns casos, diretamente pela direção. A profissão de bailarino é regulamentada pela Lei ํo 6.533/78. O DRT é emitido pelo Ministério do Trabalho mediante atestado de capacitação profissional ou diploma. Esse atestado de capacitação é emitido por entidades 
como o Sindidança (Sindicato dos Profissionais da Dança do Estado de São Paulo), o Sindicato dos Profissionais de Dança do Estado do Rio de Janeiro (SPDRJ), entre outros. O conjunto das atribuições e responsabilidades para os bailarinos é descrito formalmente: há uma denominação própria, um número certo para identificá-los na administração pública e o pagamento é realizado pelos cofres públicos, por provimento em caráter permanente ou temporário. Servidores em caráter permanente são "servidores estatutários, sujeitos ao regime estatutário e ocupando cargos públicos. Servidores temporários, contratados por tempo determinado para atender à necessidade temporária de excepcional interesse público [...]; eles exercem função, sem estarem vinculados a cargo ou emprego público" (DI PIETRO, 2010. p. 513 e 514). O "número certo" significa que cada um tem uma senha ou um código que informa a sua colocação no quadro da instituição. Essa denominação pode mudar de uma instituição para outra, mas o significado permanece o mesmo. Não há, nesse formato de contratação, diferenças entre as distintas profissões - a lei do funcionalismo público é igual para todas as áreas e o número determina o valor do salário.

Então, as companhias de dança com endereço nas fundações ou centros culturais municipais ou estaduais têm seus bailarinos regidos pelas normas das instituições e pelas leis que dispõem sobre o estatuto do servidor público civil. Outras companhias apresentam relação problemática quanto à forma de contratação, acompanhada de ruídos que ecoam até os dias de hoje: elas contratam seus bailarinos como prestadores de serviço, evitando a constatação de vínculo trabalhista. As companhias que são regidas por organizações sociais empregam os artistas pelo regime CLT (Consolidação das leis do Trabalho).

A questão da aposentadoria para bailarinos se constitui em um dos grandes impasses nessa relação com o órgão público e vem ganhando maior visibilidade nas discussões entre direções e bailarinos dessas companhias. Encontra-se nesse ponto a questão central da criação das companhias 2, pois, como os bailarinos das companhias mais antigas têm contratos vitalícios, a dificuldade está em entender o que fazer quando eles já não se enquadram nas propostas artísticas das companhias.

No Brasil, as companhias oficiais, enquanto instituições culturais representantes do poder público no cenário nacional, pedem por fundamentais e indispensáveis ajustes em suas estruturas administrativa, jurídica e artística. E sem que essas mudanças sejam realizadas, será muito difícil a invenção de um novo papel para a sua atuação no contexto cultural do qual fazem parte. 


\section{Sobre as companhias 2}

É nesse panorama de carência estrutural jurídica e administrativa que aparece a designação: companhia 2 - cia. 2. Para ela, são enviados os bailarinos que estão prestes a se aposentar. Nesse momento, os diretores chegam a um impasse: como lidar com essa situação num país onde essa profissão não é reconhecida? Como afastar um bailarino que durante muitos anos se dedicou a essa profissão e à companhia?

No Brasil, três companhias colocaram em prática esse perfil: o Balé da Cidade de São Paulo (BCSP/1968), o Balé Teatro Guaíra (BTG-PR/1969) e o Balé Teatro Castro Alves (BTCA-BA/1981). As rubricas desse novo espaço são respectivamente: Cia. 2 do BCSP, criada em 1999 e extinta em 20096; Guaíra 2 Cia. de Dança (G2), também de 19997; e BTCA 2, originado em 2004 e extinto em $2007^{8}$.

Um fator determinante para o surgimento desse modelo vincula-se à forma de contratação dos artistas. No G2 Cia. de Dança, bem como no BTCA 2, os integrantes, na grande maioria, são estatutários, quer dizer, funcionários públicos. Nesse caso, tanto no G2 como no BTCA 2, a companhia devia encontrar uma forma de propor a continuidade dos bailarinos veteranos, sendo a criação da companhia 2 uma saída. Já na companhia 2 paulistana, o caso foi diferente: como a maioria dos artistas era contratada por meio da dita "verba de terceiros", ou seja, prestadores de serviço sem vínculo empregatício com a municipalidade, o tempo de casa lhes conferia um paralelo ao regime estatutário, pois muitos lá estavam há mais de 20 anos.

Exemplificando essa situação contratual entre administração pública e artistas, no ano de 2010, a Fundação do Theatro Municipal do Rio de Janeiro lançou um novo Projeto de Lei, de oㅜ 3.017/2010, de autoria do Poder Executivo, dispondo sobre a criação de cargos comissionados para os corpos artísticos da Fundação. A proposta de criar cargos comissionados deve-se à tentativa de flexibilizar as contratações para o quadro artístico da Fundação, evitando, assim, concursos para quadros vitalícios. Carla Camurati, presidente da Fundação do Teatro Municipal ${ }^{9}$ desde outubro de 2007,

\footnotetext{
${ }^{6}$ Criada pela ex-diretora da companhia, Ivonice Satie (1951-2008). O motivo que levou a Procuradoria da Secretaria Municipal de Cultura a interromper as atividades do grupo foi por esta não ter sido constituída em forma de lei.

${ }^{7}$ Criado por Carla Heinecke, ex-diretora do Balé Teatro Guaíra.

${ }^{8}$ Criada na gestão de Antonio Carlos Cardoso, inicialmente era chamada de Cia. llimitada e dirigida por Carlos Moraes e Ivete Ramos. Em 2007, o Secretário de Cultura decidiu permanecer somente com os bailarinos estatutários, assim fundiram-se as duas companhias.

${ }^{9}$ A Fundação é subordinada à Secretaria de Estado de Cultura do Governo do Estado do Rio de Janeiro.
} 
na matéria "Rio forma e 'exporta' bailarinos para SP"10, explica que os motivos dessa situação no Ballet do Theatro Municipal Têm relação com os poucos concursos e espetáculos realizados pela companhia. Ela afirma, também, que os bailarinos são atraídos por melhores salários, referindo-se à São Paulo Cia. de Dança, para a qual migraram alguns bailarinos cariocas. Nessa mesma matéria, de 2011, do jornal O Globo, assinada por Suzana Velasco, encontra-se: "Ela ainda critica a falta de uma aposentadoria específica para os bailarinos, o que impede a vinda de mais concursos para o Balé, hoje com 120 contratados e 20 vagas temporárias"; e segue, mais adiante, enfatizando tal problemática: "A carreira do bailarino é curta, mas não existe uma aposentadoria diferente para ele. Temos uma legislação obsoleta. Muitos não podem mais dançar, mas também não podem se aposentar. Não posso abrir mais vagas no Balé".

Retomando a discussão sobre companhias 2 , ressalta-se que a problemática se inicia na observação da importância do posicionamento e do engajamento de uma instituição pública, de seus dirigentes e bailarinos, em criar um segundo grupo, percebendo-se que, ao longo de suas trajetórias, esse tipo de organização nasce para justificar uma deficiência estrutural da administração pública, e não para dar continuidade, de fato, à atuação dos artistas veteranos.

Criar outra companhia dentro da mesma estrutura não é garantia de que haverá uma transformação imediata no pensamento e no comportamento dos artistas, pois eles mudam somente de sala, permanecendo no mesmo prédio e se alimentando das mesmas informações que os guiaram durante vários anos.

A partir dessa circunstância existencial, percebe-se o que norteia essa ideia. Os bailarinos, que dançavam há vários anos na outra companhia (cia. 1), somente se deslocaram de um lugar para outro. Assim, pode-se imaginar que a produção artística deles será similar àquela que faziam antes, com a diferença de que agora eles estão um pouco mais velhos. Pretender outra ação seria fechar os olhos para a trajetória desse elenco.

A designação dada a essas companhias - cia. 1 e cia. 2 - sugere que não há uma ruptura conceitual, apenas uma linha sucessiva no tempo, do número 1 passa-se, com o tempo, para o número 2, e assim por diante, levando à pressuposição de que a proposta dessas companhias é manter o que vem sendo realizado artisticamente nessas instituições, sendo a idade dos bailarinos o pré-requisito para a inserção deles em cada companhia.

${ }^{10}$ Disponível em: http://www.aarffsa.com.br/noticias2/30011156.html. Acesso em: 20 jul. 2011. 
Tanto a Cia. 2 do BCSP como o G2 e o BTCA 2 valeram-se da mesma atitude quanto às suas identificações: apropriaram-se da mesma denominação da companhia-mãe, distinguindo-se delas apenas pela utilização do número "2"11 ao final de sua designação. Nasceram tendo como molde artístico o do NDT III (Nederlands Dans Theater III), da Holanda, que surge em 1991 e encerra suas atividades em 2006. Para o coreógrafo Jiri Kylián, diretor nesse período, o grupo foi criado para dançarinos experientes treinados na técnica clássica, com idade acima de 40 anos, com o objetivo de propor desafios artísticos apropriados para seus corpos em transformação, ampliando, assim, suas carreiras.

Destaca-se que esse formato de instituição, que se constrói a partir de princípios modelados nos padrões de outras geografias, vem acompanhado da questão de como podemos reorganizar para a nossa cultura essas contribuições que de lá vieram, de forma que essas experiências ocorram por meio de transformações dessas confluências, e não somente como cópias cuja tradução ignora o entorno. E aqui se faz necessário citar, novamente, Santos (2006, p. 129):

A tradução é, simultaneamente, um trabalho intelectual e um trabalho político. E é também um trabalho emocional porque pressupõe o inconformismo perante uma carência decorrente do caráter incompleto ou deficiente de um dado conhecimento ou de uma dada prática.

No início da formação das companhias públicas 2, no final da década de 1990, verifica-se um "acordo" de não explorar as potencialidades das esferas que pertencem a esse lugar. Assim, a dança brasileira nos meandros públicos continua a se apoiar nas distorções do "típico europeu”. O problema das companhias 2 brasileiras não está em imitar modelos; o fulcro dessa questão está na natureza da companhia-mãe e na complexidade da relação entre artistas, direções e a instituição pública.

Nessa perspectiva, pergunta-se: como é possível construir outro conceito norteando o trânsito para uma discussão política e cultural? Sem dúvida, é uma tarefa hercúlea. Apenas criticar, no entanto, é uma maneira simplista de abordar a questão, por isso é necessário elaborar um conhecimento sob a forma de teoria crítica, mesmo sendo uma teoria em processo. Canclini (1980, p. 20) aborda a associação entre a arte e o conhecimento da sociedade:

Não duvidamos de que a arte possa contribuir - junto com outras vias de estudo - para o conhecimento de uma sociedade, mas para situar o valor da informação artística, deve-se estabelecer primeiro, como a arte está inserida

\footnotetext{
${ }^{11}$ Ao se empregar o número "2", a companhia matriz passa a ser designada com o número "1".
} 
no contexto, em que medida sofre seus condicionamentos e em que medida é capaz de tornar a agir sobre eles e produzir um conhecimento efetivo.

Dessa forma, o autor propõe que urge a necessidade de uma pluralidade de projetos coletivos articulados de modo não hierárquico e que estejam atentos aos processos de tradução que substituiriam a formulação de uma teoria geral para uma teoria cada vez mais específica e localizada, entendendo os desdobramentos, nos dias de hoje, dessa formação sem as devidas adequações.

Sob essa perspectiva, a implementação de outros processos para que as convergências das culturas no âmbito artístico-político se realizem, que permitam vislumbrar uma rota mais viável à criação dessas companhias, ainda está inoperante. Dessa forma, a ideia da abertura dessas companhias parece ser uma forma velada de justificar a transferência, da companhia dita "principal" para a companhia 2, de bailarinos que não estão mais aptos a seguir com seu trabalho de rotina. Tudo indica que é complicado para os dirigentes adotarem outros procedimentos, propondo outras funções para esses artistas dentro da grande estrutura, pois, para assumirem que a finalidade da companhia é explorar a pesquisa e a investigação, eles devem entender a natureza dos artistas que compõem esse companhia e que:

\begin{abstract}
As relações entre o corpo e o ambiente se dão por processos co-evolutivos que produzem uma rede de pré-disposições perceptuais, motoras, de aprendizado e emocionais. Embora o corpo e ambiente estejam envolvidos em fluxos permanentes de informação, há uma taxa de preservação que garante a unidade e a sobrevivência dos organismos e de cada ser vivo em meio à transformação constante que caracteriza os sistemas vivos. Mas o que importa ressaltar é a implicação do corpo no ambiente, que cancela a possibilidade de entendimento do mundo como objeto aguardando um observador. (KATZ, 2005, p. 130)
\end{abstract}

Ao longo da existência da Cia. 2, do G2 Cia. de Dança e do BTCA 2, pouco se soube ou se falou dessas companhias, que tinham algum destaque apenas na ocasião do seu surgimento ou quando alguma criação ganhava destaque na cena da dança de suas localidades. Elas viviam em regime de pouca visibilidade, pois a luz dos holofotes incidia, geralmente, sobre a companhia-mãe. Os registros sobre elas são vagos e insuficientes, e a maior parte das informações se encontra nos sites, em poucas críticas de jornais ou em alguns artigos dos livros comemorativos dessas companhias. Nos trechos extraídos de textos nas mídias eletrônicas de cada instituição, bem como de programas dos espetáculos, as expressões "dança contemporânea", "experiência", "intérprete-criador", "criação coletiva," "pesquisa de linguagem", entre outras, são recorrentes, justificando a sua existência no cenário artístico em vigor, operando como 
uma espécie de passaporte, que, muitas vezes, não legitimava, e sim mascarava a natureza artística delas. A falta de suporte conceitual fez com que as companhias 2 se tornassem somente estoques de boas intenções, em vez de se constituírem em alternativa político-artística para a chamada longevidade, maturidade e continuidade de seus artistas.

Muitas questões são pertinentes e devem ser levantadas no intento de construir um projeto artístico para que o surgimento de companhias dessa natureza tenha uma função efetiva para a dança pública brasileira. Tornam-se fundamentais as perguntas: poder-se-ia almejar a criação de um espaço que tivesse outra função dentro dessas companhias? Essa é uma iniciativa necessária? O que pretendem os bailarinos que integram esse tipo de estrutura oficial, no que diz respeito ao desdobramento de sua carreira artística? Se eles estão há tanto tempo no mesmo lugar, fazendo os mesmos trabalhos, discutindo a partir do padrão de conhecimentos inerentes a essas instituições, o que se poderá esperar deles nessa outra companhia? Será a idade condição suficiente para desenvolver um projeto que tenha na pesquisa o seu principal alicerce? Presumir que um estabelecimento público que mantém duas companhias deve manter os mesmos modos de atuação artística para elas, considerando unicamente como diferença entre elas o fator da idade, é desprezar a arte em suas possibilidades de produzir conhecimento. Ao mesmo tempo, vislumbrar um processo artístico que evidencie outro modo de fazer dança acarreta um não entendimento da singularidade dos bailarinos que compõem essas companhias.

Ao se observar que a trajetória dos bailarinos que compõem a Cia. 2 foi construída a partir dessa intrincada engrenagem, entende-se que deve ter havido certa dificuldade de adaptação nesse outro lugar. Os artistas enfrentam essa situação crítica no momento em que são retirados de uma sala e colocados em outra, com o peso de terem que se aventurar na dança da maturidade "acumulada" ao longo de suas vidas e transformá-la na dança de pesquisa e investigação.

Se a produção de conhecimento nesses lugares está sendo desenvolvida a partir dos mesmos parâmetros, também significa que ela permanece obstinada no pensamento que constrói uma estrutura estabelecida com base nos princípios das normas habituais e enrijecidas da própria instituição. Assim, seus procedimentos artísticos continuarão dando vazão à noção de um lugar cujo alicerce está completa- 
mente ligado ao pensamento cultural, político, ideológico e social dos conceitos clássicos estrangeiros. O insistente retorno à questão das estruturações da dança nos meandros públicos, seguindo uma tradução equivocada do modelo centro-europeu, faz-se com o propósito de salientar esse grande problema que vem desde meados do século $X X$.

Dessa forma, poder-se-ia constatar que o surgimento desse outro grupo na mesma estrutura corrobora a ideia de continuar com esses bailarinos no quadro artístico, seja por terem contratos vitalícios, seja por se tornarem "vitalícios" por tempo de casa. Demitir um profissional que atuou mais de 15, 18, 20 anos numa companhia não é tarefa fácil para uma direção que muda, geralmente, a cada quatro anos, quase sempre em função do período eleitoral.

Outro fator que pode ser trazido à tona é que parece haver um desejo em manter as aparências, privilegiando-se um aspecto atual e arrojado nessas organizações públicas, mesmo que mantendo um entendimento linear de oficialidade: o da escola para a companhia, da companhia 1 para a companhia 2, e assim sucessivamente, tentando-se manter a hierarquia, a "tradição".

De 1999 até 2011, duas companhias foram extintas e a única que sobrevive é o G2 Cia. de Dança, que mantém suas atividades em completa invisibilidade. Se houver interesse de todos os envolvidos nessas questões, é possível que o sistema da oficialidade e os artistas deixem a contramão dos modelos que optaram por implementar, descortinando a deficiência estrutural que os rege e passando a fluir a partir de outros princípios. Assim, foge-se da pasteurização e faz-se emergir um referencial direcionador que contemple pluralidades em um sistema singular, regido por descobertas que legitimem a importância de sua existência.

Bailarinos, diretores e poder público precisam estabelecer suas competências diante desse conjunto problemático de existência, o que, obviamente, demanda um trabalho de várias mãos e paciência refinada para modificar esse quadro e entender que uma companhia oficial não é uma repartição pública. Qual o caminho possível de mudança? Será que existe outra forma de engajamento com o poder público que viabilize a produção de arte com suas necessidades específicas, e não com excesso de regulamentos distantes do seu fazer? É evidente a necessidade de mudanças estruturais nessas instituições públicas visando realmente a caminhos para um desenvolvimento mais efetivo da arte que produzem. 
A crítica de dança Helena Katz chama a atenção, lembrando que:

A necessidade de as companhias oficiais repensarem o seu papel no cenário da dança de hoje é urgente. O mundo mudou muito nos últimos 400 anos, desde que a Ópera de Paris se tornou o projeto copiado em todos os cantos. Desapareceu o modelo de um Estado que provê a sustentação de um teatro municipal e suas companhias residentes. Cada vez mais, a sua continuidade depende da iniciativa privada. Em um Brasil regido por dinheiro público via Leis de Incentivo à Cultura, isso significa que as companhias oficiais se tornaram concorrentes das particulares, pois passaram a disputar com elas fatias de um mesmo bolo. ${ }^{12}$

O artista público, com receio de se posicionar, vive em estado de silêncio, dando vazão à experiência vivida somente após seu desligamento total da instituição, mas ainda assim com resguardo. Os depoimentos ouvidos da maioria dos ex-bailarinos e ex-diretores das companhias deixam transparecer o receio de trazer à tona qualquer questão concernente às relações de poder entre a soberania administrativa e os artistas. Assim, torna-se mais do que urgente repensar esse modo operante em vigor. Sem autonomia de trabalho, de organização, de decisão, artistas e diretores vão encontrando meios de sobrevivência no ambiente da oficialidade, o que promove relações complexas, ruidosas, temerosas e distantes da função que thes cabe, ou seja, de representarem um município ou um estado. As análises de Morin (2005, p. 31) sobre determinismo cultural e efervescências da cultura auxiliam na compreensão dessa forma de censura que excluiu a possibilidade de outra manifestação artística:

[...] nas macroestruturas, a normalização manifesta-se de maneira repressiva ou intimidatória, calando os que teriam a tentação de duvidar ou de contestar, reinando a ideia do incontestável reduzindo os desviantes e os desvios ao silêncio, ao esquecimento ou ao ridículo.

\section{Referências}

CANCLINI, Nestor Garcia. A socialização da arte. São Paulo: Cultrix, 1980.

DI PIETRO, Maria Sylvia Zanella. Direito Administrativo. 23. ed. São Paulo: Atlas, 2010.

GUEST, Ivor. Le Ballet de l'Opéra de Paris: trois siècles d'histoire et de tradition. Traduction de Paul Alexandre. Paris: Théâtre National de l'Opéra, 2001.

HOUAISS, Antônio; VILLAR, Mauro de Salles. Dicionário Houaiss da Língua Portuguesa. Rio de Janeiro: Objetiva, 2009.

KATZ, Helena. Por uma teoria do corpomídia. In: GREINER, Christine. O corpo: pistas para estudos indisciplinares. São Paulo: AnnaBlume, 2005.

Um trajeto de fios e teias. In: CURI, Norma; NAVAS, Cássia (Org.). Balé da Cidade de

12 KATZ, Helena. Castro Alves celebra 25 anos de seu corpo de baile. O Estado de São Paulo, São Paulo, 14 dez. 2006. Disponível em: http://www.helenakatz.pro.br/midia/helenakatz71170169994.jpg. Acesso em: 8 ago. 2011. 
São Paulo. 1. ed. São Paulo: Formarte, 2003. v. 1.

MORIN, Edgar. O método 4: as ideias. Tradução de Juremir M. da Silva. 4. ed. Porto Alegre: Sulina, 2005.

SANTOS, Boaventura de Souza. A gramática do tempo: para uma nova cultura política. São Paulo: Cortez, 2006. (Coleção Para um Novo Senso Comum, v. 4).

THOMPSON, John B. A mídia e a modernidade. Petrópolis, RJ: Vozes, 1995.

\section{Outros links}

Ballet do Theatro Municipal do Rio de Janeiro

Guaíra 2 Dança

Academia Real de Dança 